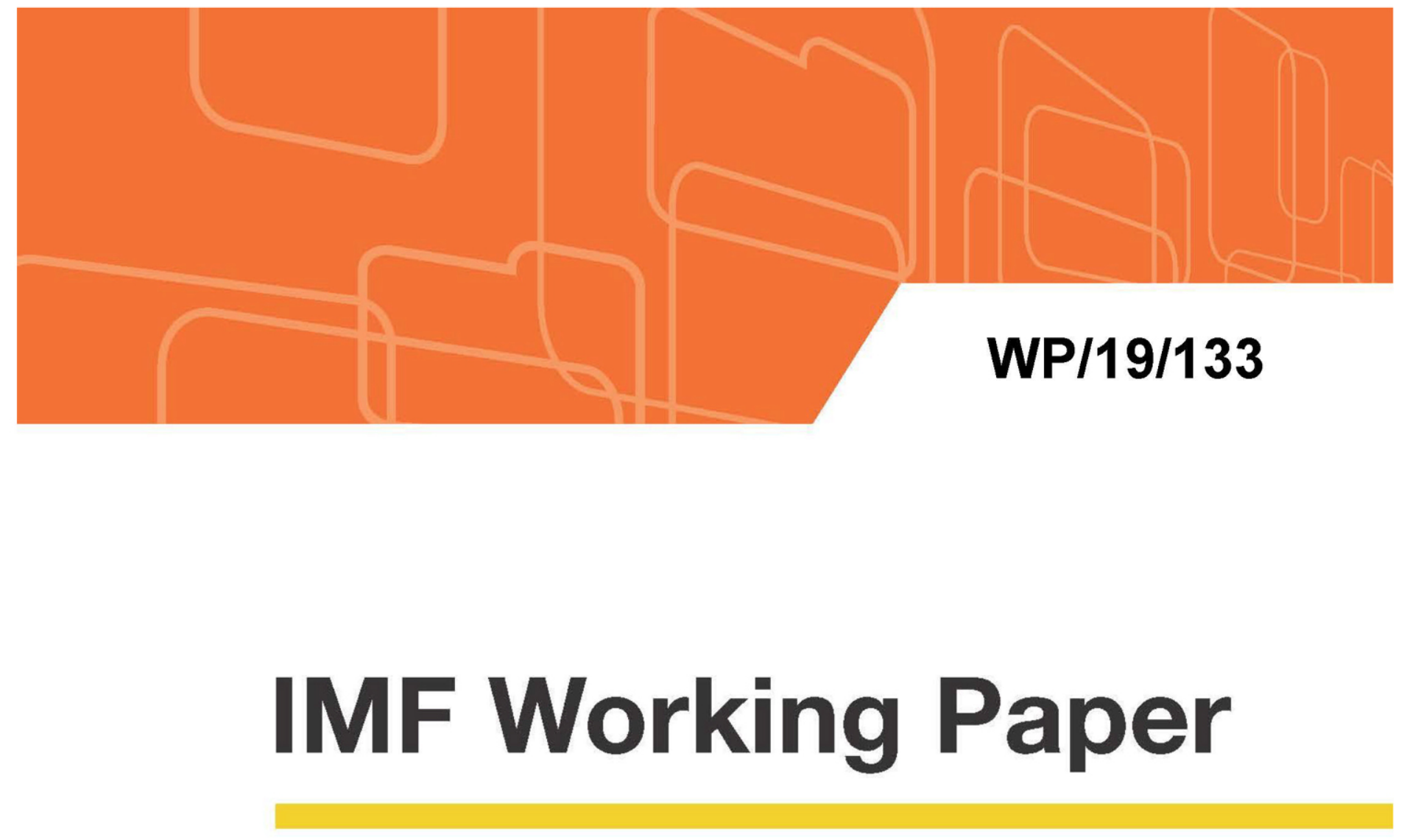

\title{
The Euro-Area Government Spending Multiplier at the Effective Lower Bound
}

by Adalgiso Amendola, Mario di Serio, Matteo Fragetta and Giovanni Melina

IMF Working Papers describe research in progress by the author(s) and are published to elicit comments and to encourage debate. The views expressed in IMF Working Papers are those of the author(s) and do not necessarily represent the views of the IMF, its Executive Board, or IMF management.

I N T E R N A T I O N A L M O N E T A R Y F U N D 


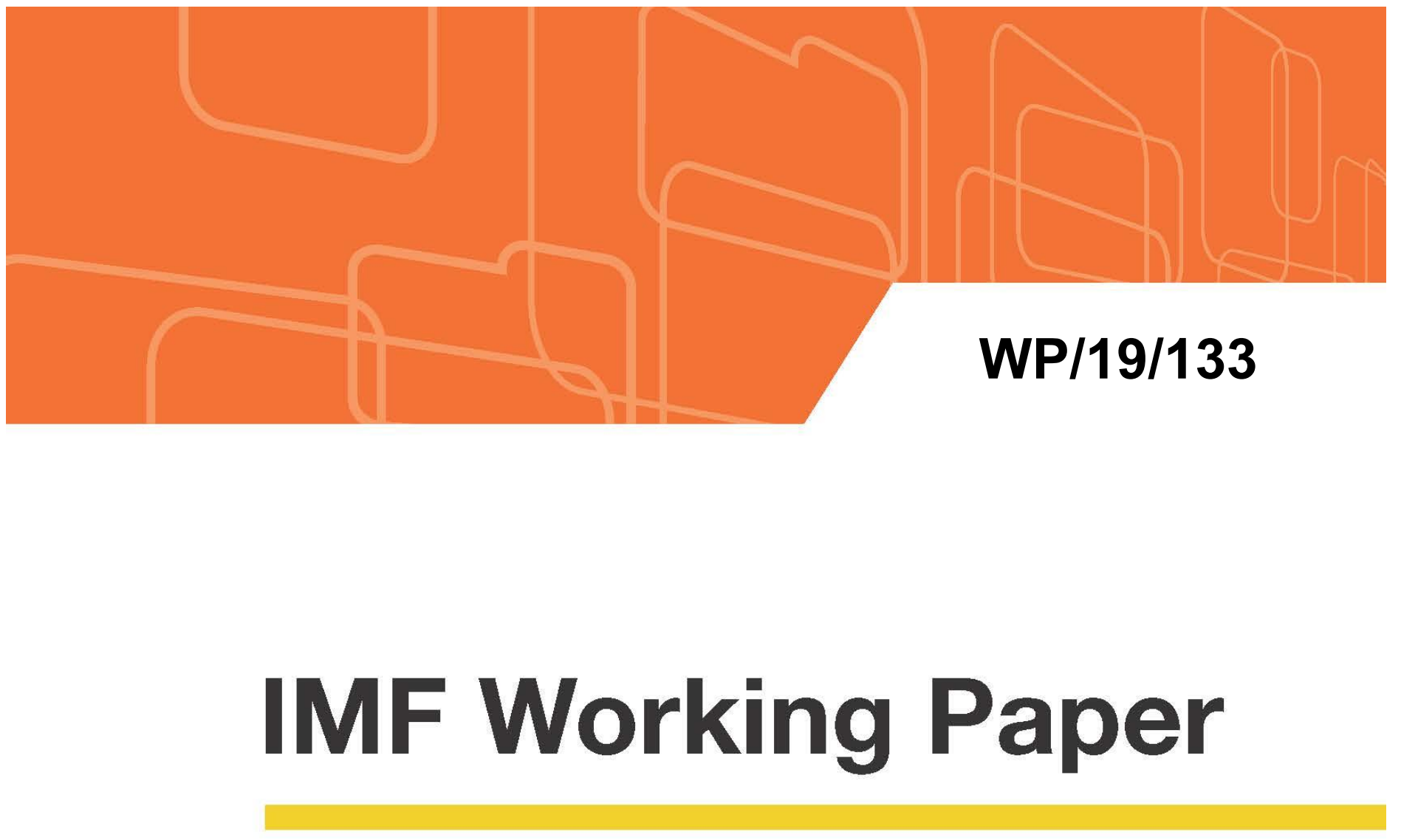

\section{The Euro-Area Government Spending Multiplier at the Effective Lower Bound}

by Adalgiso Amendola, Mario di Serio, Matteo Fragetta and Giovanni Melina

IMF Working Papers describe research in progress by the author(s) and are published to elicit comments and to encourage debate.

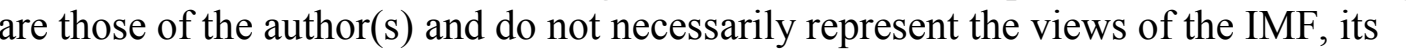

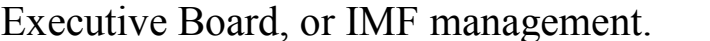

I N T E R N A T I O N A L M O N E T A R Y F U N D 


\title{
IMF Working Paper
}

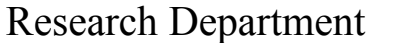

The Euro-Area Government Spending Multiplier at the Effective Lower Bound* Prepared by Adalgiso Amendola, Mario di Serio, Matteo Fragetta and Giovanni Melina

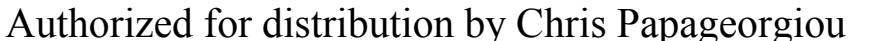

June $\square \| \square$

IMF Working Papers describe research in progress by the author(s) and are published to elicit

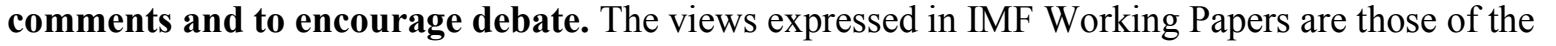

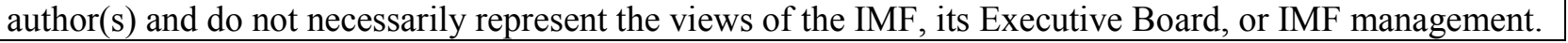

\begin{abstract}

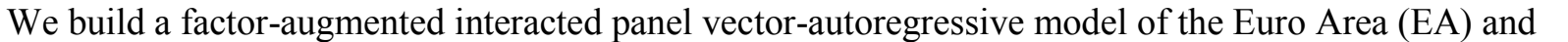

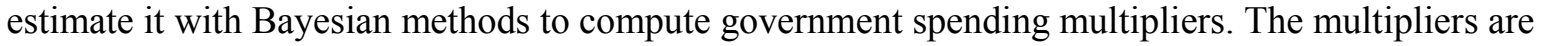

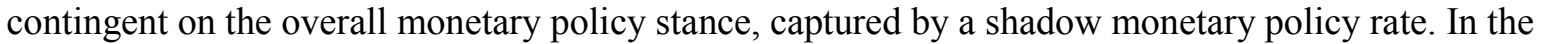

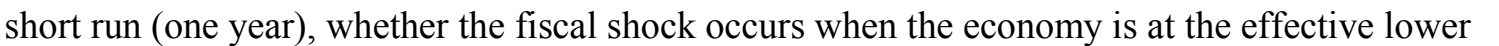

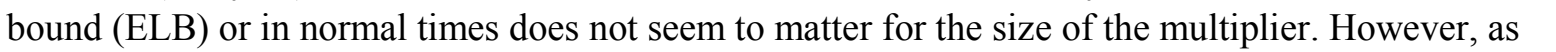

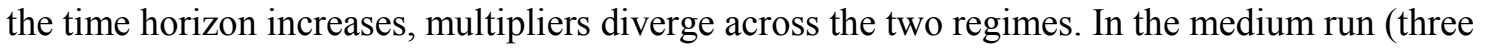

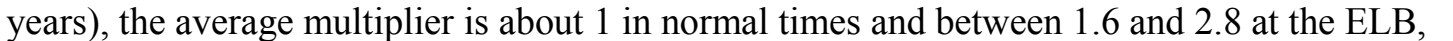

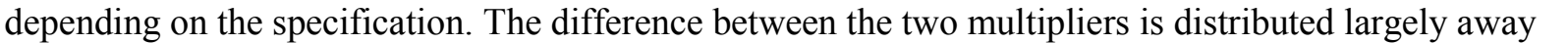

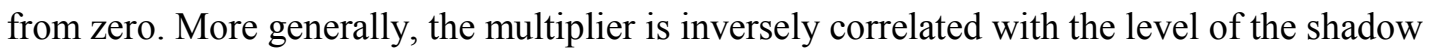

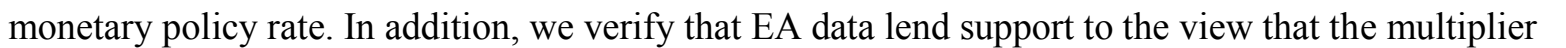

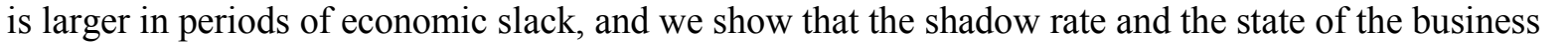

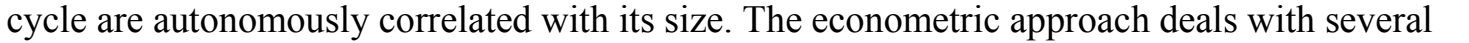

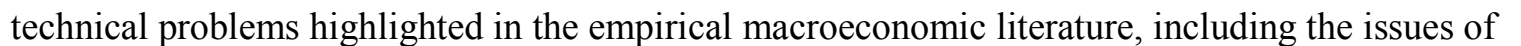

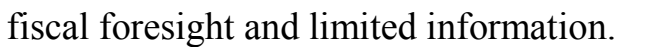

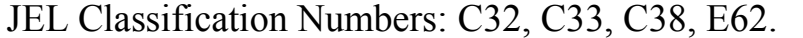

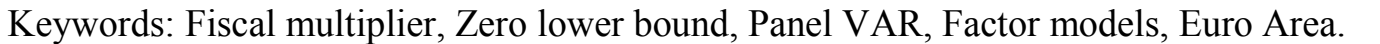

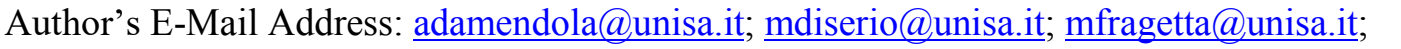

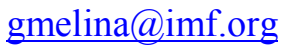

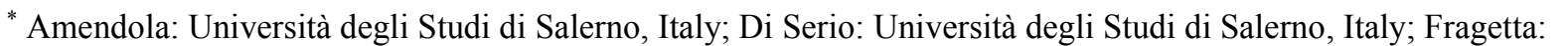

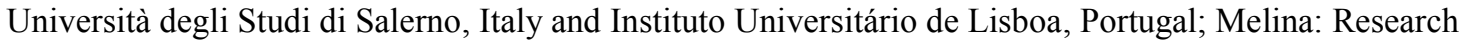

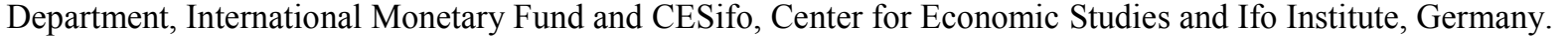

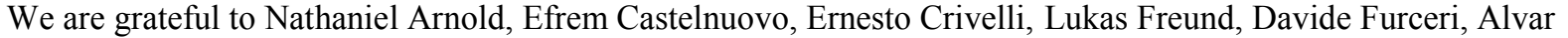

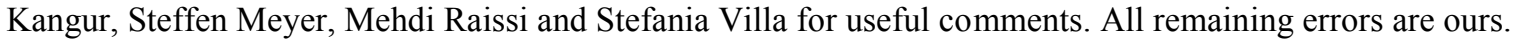

CInternational Monetary Fund. Not for Redistribution 


\section{Contents}

1 Introduction $\quad \underline{5}$

2 Methodology $\underline{8}$

2.1 Empirical Model . . . . . . . . . . . . . . . . . 8

2.2 Data and Baseline Specification . . . . . . . . . . . . . . 10

2.3 Inference, Identification and Computation of Cumulated Government Spending Multipliers . . . . . . . . . . . . . . . . . . . . 12

3 Results $\quad \underline{14}$

3.1 Impulse Responses Conditional on the Shadow Rate . . . . . . . . . . . . 14

3.2 Cumulated Government Spending Multipliers Conditional on Shadow Rate Levels .......................... . . . . . 16

3.3 Average Cumulated Government Spending Multipliers in Normal Times and the ELB . . . . . . . . . . . . . . . . . . . . . 17

3.4 Correlations of the Multiplier with the Shadow Rate and the Business Cycle $\underline{19}$

4 Robustness Checks $\quad \underline{22}$

5 Conclusions $\quad \underline{24}$

Appendix $\quad \underline{30}$

A Data $\quad \underline{30}$

A.1 Endogenous Variables . . . . . . . . . . . . . . . . . $\underline{30}$

A.2 Exogenous Variables . . . . . . . . . . . . . . . . . . $\underline{30}$

A.3 Informational Dataset . . . . . . . . . . . . . . . . . 30

A.4 Business Cycle Indicator . . . . . . . . . . . . . . . . . $\underline{31}$

B Additional Robustness Checks $\quad \underline{32}$

\section{List of Tables}

1 Sign Restrictions for Identifying the Government Spending Shock. . . . . . . 13

2 Cumulated Government Spending Multipliers Conditional on Two Levels of the Shadow Rate Representative of Normal Times and the ELB. . . . . . . . $\underline{16}$

3 Average Cumulated Government Spending Multipliers in Normal Times and at the ELB. . . . . . . . . . . . . . . . . . . . 17 
4 Conditional Correlations of Cumulated Multipliers with the Lagged Shadow Rate and the Lagged Business Cycle. . . . . . . . . . . . . . 21

5 Robustness Checks on the Average Cumulated Government Spending Multipliers in Normal Times and at the ELB. . . . . . . . . . . $\underline{23}$

6 Robustness Checks on the Distributions of Differences between Average Cumulated Government Spending Multipliers between Normal Times and the

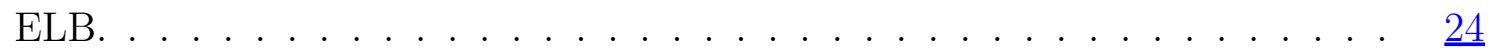

7 Robustness Checks on Conditional Correlations of Cumulated Multipliers with the Lagged Shadow Rate and the Lagged Business Cycle. . . . . . . . . 25

B.1 Conditional Correlations of Cumulated Multipliers with the Contemporaneous Shadow Rate and the Contemporaneous Business Cycle. . . . . . . . . $\underline{32}$

B.2 Robustness Checks on Conditional Correlations of Cumulated Multipliers with the Contemporaneous Shadow Rate and the Contemporaneous Business Cycle. $\underline{32}$

\section{List of Figures}

1 Euro Overnight Index Average (Eonia) Rate and Shadow Monetary Policy Rate in the Euro Area. . . . . . . . . . . . . . . $\underline{6}$

2 Impulse Responses to a Government Spending Shock in Normal Times and at

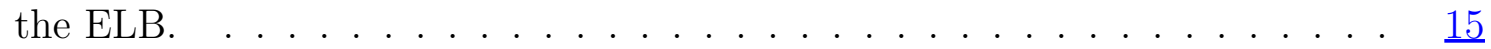

3 Distributions of Differences in Cumulated Government Spending Multipliers between Two Levels of the Shadow Rate Representative of Normal Times and

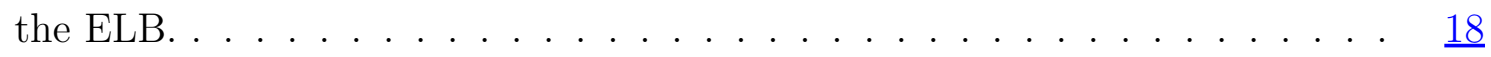

4 Distributions of Differences in Average Cumulated Government Spending Multipliers between Normal Times and the ELB. . . . . . . . . . $\underline{20}$ 


\section{Introduction}

The Global Financial Crisis (GFC) and the subsequent Great Recession pushed many governments in advanced economies - notably the US, EU member countries and Japan - to use fiscal policy as a discretionary tool to soften the adverse effects of the economic contraction. In 2008 the European Commission launched the "European Economic Recovery Plan" (EERP) to provide fiscal stimulus to the euro area (EA) economies. More recently, some EA countries experienced fiscal shocks of opposite sign as their governments went through austerity measures to put their finances back on track in response to the EA sovereign debt crisis.

In both types of situations, policymakers are confronted with a crucial question: what is the size of the government spending multiplier? While at the onset of the GFC there was already a large literature providing estimates of this multiplier, in academic and policy circles alike it became soon clear that those estimates were likely not applicable to the new economic environment. One reason is that after the GFC, monetary policy ceased to operate in the conventional way. The policy rate was lowered repeatedly until it reached its effective lower bound (ELB), and the ELB itself turned out to be a dynamic concept. While at the beginning of the GFC it was believed to coincide with the zero lower bound (ZLB), at a certain point several central banks - the European Central Bank (ECB), Danmarks Nationalbank, Sveriges Riksbank, Swiss National Bank, and Bank of Japan - adopted negative interest rate policies. Negative interest rates were not the only unconventional measures. Central banks started implementing also asset purchase programs (APP, often dubbed as quantitative easing-QE), and forward guidance to affect long-term interest rates and boost aggregate demand.

Focusing on the EA, this paper seeks to answer the following question: when monetary policy is constrained by the ELB and operates in an unconventional manner, is the government spending multiplier different from the multiplier observed in normal times?

In theory when the ZLB is strictly binding, an increase in government spending leads to a bigger rise in expected inflation, which drives down the real interest rate and in turn boosts private spending to a larger extent, ultimately delivering a larger multiplier effect (see, e.g., Christiano et al., 2011). Several theoretical contributions have investigated numerous factors that may alter this basic result. In any case, as briefly described above, monetary policy in the EA has lately been much more complex than any theory. This is why, in this paper, we

prefer to tackle this important question from a purely empirical viewpoint. To overcome the difficulty of capturing the recently enhanced policy intricacy, our approach is to condition the computation of the multiplier on an indicator that summarizes the overall monetary policy stance into account. A prominent indicator with this desirable features has recently 
Figure 1: Euro Overnight Index Average (Eonia) Rate and Shadow Monetary Policy Rate in the Euro Area.

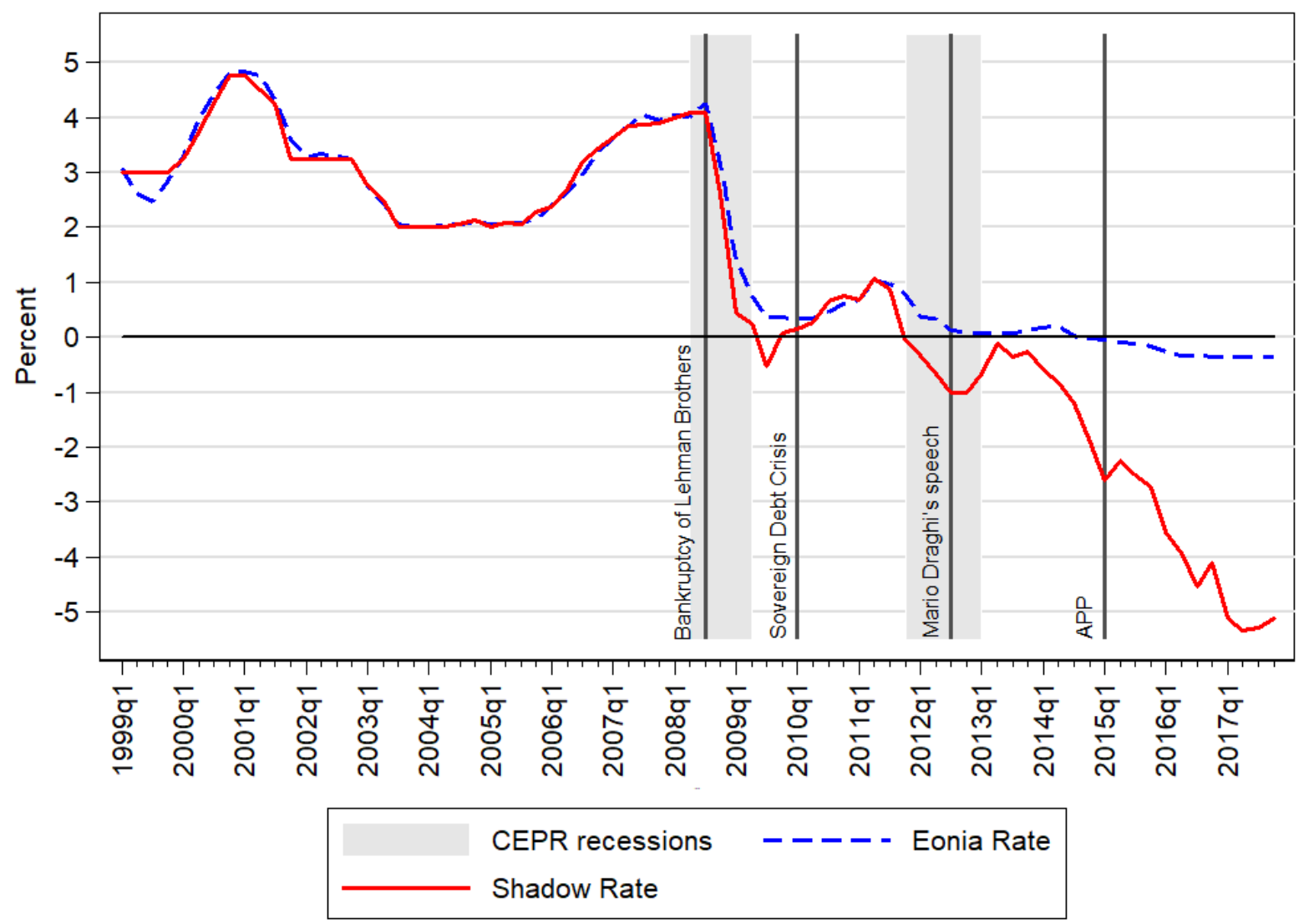

Sources: European Central Bank and Wu and Xia (2017).

been the shadow rate (SR) derived by Wu and Xia (2016) and Wu and Xia (2017) using an approximation of a nonlinear term structure model. In Figure 1 we report the EA shadow rate along with the observed euro overnight index average (Eonia) rate. The two rates almost overlapped before the inception of the GFC. They started to diverge after 2008q3, a quarter made infamous in economic history by the bankruptcy of Lehman Brothers. Then, after the well-known "Whatever it takes" speech of ECB's President Mario Draghi, the Eonia rate was brought first to the ZLB and then turned negative, while the SR continued to sink into the negative territory.

To fully take the dynamics of the shadow rate into account, we use a factor-augmented interacted panel vector-autoregressive model purified of expectations (FAIPVAR-X), an extension of the IPVAR model by Towbin and Weber (2013) and Sá et al. (2014). Using this framework has four advantages. First, the panel dimension allows exploiting quarterly data of ten EA countries (Austria, Belgium, Finland, France, Germany, Ireland, Italy, Nether- 
lands, Portugal and Spain) that were part of the European Monetary Union (EMU) since its inception. ${ }^{1}$ Second, the presence of an interaction term allows capturing nonlinearities and estimating the reaction of the variables of interest to a government spending shock at each percentile of the shadow rate. Third, augmenting the specification with factors extracted from a large number of macroeconomic variables addresses limited information concerns. In fact, there is likely important information that we do not explicitly include in our model, but that might have been used by economic agents in making their choices (see Bernanke et al., 2005; Stock and Watson, 2005; Fragetta and Gasteiger, 2014). Fourth, including forecasts of government spending as an exogenous variable purges government spending shocks from its anticipated component and addresses the issue of fiscal foresight (see, e.g., Forni and Gambetti (2010), among others). Addressing the issues of limited information and fiscal foresight resolves what the literature calls non-fundamentalness, a problem stemming essentially from a misalignment between the information sets of economic agents and the econometrician. Failing to rectify this problem would bias the results.

Turning to the answer to our research question, our findings are as follows: (i) in the short run (one-year horizon), the average cumulated government spending multiplier does not seem to depend on whether the fiscal shock occurs when the economy is at the ELB or in normal times; (ii) as the time horizon increases, multipliers diverge across the two regimes with normal times displaying a decay in the cumulated multiplier; (iii) at an intermediate horizon (three years), the average multiplier is about 1 in normal times and between 1.6 and 2.8 at the ELB, depending on the specification, with their difference being distributed largely away from zero; (iv) more generally, the multiplier is inversely correlated with the level of the shadow rate. We also find its size to be inversely correlated with the business cycle after controlling for the level of the shadow rate, lending support to the view that the multiplier is larger in periods of economic slack (in line, e.g., with Auerbach and Gorodnichenko, 2013). Furthermore, we verify that the shadow rate and the state of the business cycle are autonomously correlated with its size.

Our paper is related to a number of contributions in the literature. The literature that uses calibrated or estimated dynamic stochastic general equilibrium (DSGE) models does not agree on whether, or in which direction, a binding ZLB for the monetary policy rate should alter the government spending multiplier. ${ }^{2}$ A number of contributions (Christiano et al., 2011; Coenen et al., 2012; Davig and Leeper, 2011; Eggertsson, 2010; Kilponen et al., 2015; Woodford, 2011, among others) argue in favor of a higher multiplier at the ZLB. According

\footnotetext{
${ }^{1}$ In line with Auerbach and Gorodnichenko (2013), we exclude Luxembourg being it a small economy with large and volatile changes in government spending series.

${ }^{2}$ In DSGE models the ELB typically coincides with the ZLB.
} 
to these studies, the government spending multiplier at the ZLB is in the range of 2 to 5 . In contrast, a host of equally rigorous papers (Cwik and Wieland, 2011; Braun et al., 2013; Mertens and Ravn, 2014; Aruoba et al., 2017, among others) claim the multiplier to be small at the ZLB, sometimes even smaller than in normal times. We ascribe this disagreement to the inherent difficulty in building DSGE models encompassing all the complexity that characterized monetary policy making in the aftermath of the GFC. In the empirical literature, although with a different methodology than ours, Ramey and Zubairy (2018) estimate the U.S. government spending multiplier at the ZLB. They find mixed results that depend on the sample period. When excluding the World War II period, they find a multiplier at the ZLB up to 1.5. To our knowledge, the literature lacks empirical estimates of the multiplier at the ELB for the EA. ${ }^{3}$ We fill in this gap. By conditioning the multiplier on the level of the shadow rate over virtually the entire history of the EMU, the choice of the estimation sample ceases to be an issue. Furthermore, our estimation strategy implies studying not only how the size of the multiplier is affected by the ELB, but also by the whole set of unconventional monetary policies implemented after the GFC in the eurozone. An issue we leave aside is a further distinction between times or countries with high versus low public debt. ${ }^{4}$ Ours are average results for the EA and the focus is on the interaction with the monetary policy stance.

The remainder of the paper is structured as follows. Section 2 explains the empirical methodology and the econometric specification. Section 3 reports the results. Section 4 presents robustness checks. Finally, Section 5 concludes. Data sources and further robustness checks are appended to the paper.

\section{Methodology}

\subsection{Empirical Model}

The empirical model builds on the Interacted Panel Vector Auto-Regressive (IPVAR) framework developed by Towbin and Weber (2013) and Sá et al. (2014). This model is well suited to our purposes because the presence of interaction terms allows us to capture nonlinearities in the reaction of variables of interest to government spending shocks conditional on the

\footnotetext{
${ }^{3}$ Cwik and Wieland (2011), Coenen et al. (2012) and Kilponen et al. (2015) investigate the issue in DSGE models of the EA, while Bonam et al. (2017) perform an empirical investigation using OECD countries including some EU economies, but no purely empirical study has focused specifically on the EA.

${ }^{4}$ There are theoretical (see, e.g., Sutherland, 1997; Perotti, 1999; Bi et al., 2016) and empirical (see, e.g., Kirchner et al., 2010; Ilzetzki et al., 2013; Nickel and Tudyka, 2014) contributions highlighting that if a government spending expansion occurs when public debt is high, the fiscal multiplier will be lower because private agents expect a more imminent and larger increase in taxes.
} 
whole distribution of the nominal shadow interest rate.

The model specification takes the following general structural form:

$$
\begin{aligned}
B_{i, t} y_{i, t} & =\sum_{j=1}^{N} \kappa_{j} D_{j, i}+\sum_{j=1}^{N} \sum_{k=1}^{L} \Gamma_{j, k} D_{j, i} y_{i, t-k}+\sum_{j=1}^{N} \kappa_{j}^{1} D_{j, i} x_{t}+\sum_{k=1}^{L} \Gamma_{k}^{1} x_{t} y_{i, t-k} \\
& +\sum_{j=1}^{N} v_{j} f_{(t \mid t-1: t-4)}+v^{1} z_{t-1}+\varepsilon_{i, t},
\end{aligned}
$$

where $t=1, \ldots, T$ denotes the time dimension; $j=1, \ldots, N$ denotes the country dimension; and $k=1, \ldots, L$ represents the lag structure. The vector of endogenous variables is denoted by $y_{i, t}$; the interaction term is represented by $x_{t}$; while the vectors of two sets of exogenous variables are denoted by $f_{(t-1: t-4)}$ (discussed in Subsection 2.2) and $z_{t-1}$ (foreign exogenous variables, also discussed in Subsection 2.2). Furthermore, coefficient $\kappa_{j}$ is the country-specific intercept of country $j ; \kappa_{j}^{1}$ is the country-specific coefficient of the interaction term; $\Gamma_{j, k}$ is the matrix of autoregressive coefficients attached to the endogenous variables; $\nu_{j}$ is the matrix of country-specific coefficients attached to the first set of exogenous variables; $v^{1}$ represents the pooled estimated coefficients of the another set of exogenous variables; $D_{j, i}$ is an indicator variable for each country (equal to 1 if $i=j$, and 0 otherwise); and, lastly, $\varepsilon_{i, t}$ is a vector of i.i.d. residuals, which are uncorrelated across countries by assumption. It is noteworthy that the interaction term, $x_{t}$, affects both the level and the dynamic relationship across endogenous variables through $\kappa_{j}^{1}$ and $\Gamma_{k}^{1}$ (for more technical details on the IPVAR framework see, e.g., Sá et al., 2014).

To allow for as much heterogeneity as possible, we utilize a panel model with fixed effects and heterogeneous slopes, which we estimate using the mean group estimator. This estimator has been shown to perform better than alternative estimators in dynamic panels (see, e.g., Pesaran and Smith, 1995 and Canova and Ciccarelli, 2013, among others). Due to data availability constraints we estimate homogeneous slopes of lagged interacted terms, $x_{t} y_{i, t-k}$, and foreign exogenous variables, $z_{t-1}$.

Matrix $B_{i, t}$ is a $(q \times q)$ lower triangular matrix with ones on the main diagonal. The recursive structure imposed on matrix $B_{i, t}$ implies that the covariance matrix of the residuals, $\Sigma_{\varepsilon}$, is diagonal. Given that the FAIPVAR-X model requires the estimation of a large number of parameters, for the sake of parsimony, we produce the baseline results with a uniform lag structure on one quarter $(L=1)$. We re-run the estimation also with two lags for robustness (Section 4). 


\subsection{Data and Baseline Specification}

Our dataset is composed of quarterly data and covers the period from $2002 \mathrm{q} 2$ to $2017 \mathrm{q} 4 .{ }^{5}$ We consider ten of the eleven countries that joined the EA when it came into existence: Austria, Belgium, Finland, France, Germany, Ireland, Italy, Netherlands, Portugal and Spain. In line with Auerbach and Gorodnichenko (2013), we exclude Luxembourg being a small economy, which exhibits large and volatile changes in government spending series. For details on the construction of the dataset, see Appendix A.

To examine the macroeconomic effects of fiscal shocks, the VAR literature has traditionally used variations of the following vector of endogenous variables:

$$
y_{i, t}=\left[G_{i, t}, G D P_{i, t}, T_{i, t}\right]^{\prime}
$$

where $G_{i, t}, G D P_{i, t}$ and $T_{i, t}$ represent real government purchases (the sum of government gross fixed capital formation and government consumption), real gross domestic product and real net taxes (the sum of government receipts of direct and indirect taxes minus transfers to businesses and individuals), respectively. We make a number of modifications to this simple specification to overcome a series of issues we discuss below.

First, to simplify the procedure related to the computation of government spending multipliers, we divide all endogenous variables by the real potential GDP of the corresponding country. This way there is no need to take the logarithm of the variables and perform ex-post conversions of the estimated elasticities to dollar equivalents, avoiding potential biases. In fact, ex-post conversion requires the use of constant sample averages of the ratios of fiscal variables to GDP, which may instead vary over time, potentially biasing the size of the multipliers. This problem is even more acute in nonlinear models, such as that adopted in this paper (for more details on this issue see, e.g., Gordon and Krenn, 2010 and Ramey and Zubairy, 2018, among others). We compute real potential GDP using the filter recently proposed by Hamilton (2018), which avoids the spurious persistence in the cyclical component implied by the traditional Hodrick-Prescott (HP) filter.

Second, to the basic set of endogenous variables listed in vector $y_{i, t}$, we add common factors, via principal components, extracted from a large number of macroeconomic times series. In fact, VAR models are characterized by a trade-off between parsimony and omission of relevant variables, which can give rise to nonfundamentalness of the identified shocks (see, e.g., Forni et al., 2009). Extracting information from a large set of macroeconomic variables overcomes the limited information problem because the principal components proxy the

\footnotetext{
${ }^{5}$ The beginning of our sample is dictated by the availability of the Economist Intelligence Unit forecasts of government spending, the use of which is explained below.
} 
unobserved factors affecting most macroeconomic variables (see Fragetta and Gasteiger, 2014 for further details). Similar to Bernanke et al. (2005), we implement a two-step estimation procedure. As a first step, we extract five common factors, as established by the Bai and $\mathrm{Ng}$ (2007) $I C_{p 2}$ information criterion. The second step is adding the five factors to our vector of endogenous variables, which reads as follows:

$$
y_{i, t}=\left[G_{i, t}, G D P_{i, t}, T_{i, t}, F_{t}\right]^{\prime}
$$

where $F_{t}$ is a $1 \times 5$ vector common to all countries, but that may have a different impact in each country, capturing also potential spillovers across countries.

Third, among the exogenous variables, we add the $f_{(t \mid t-1: t-4)}$ series. This represents the forecast of time- $t$ government spending over the past 12 months (four quarters), published by the Economist Intelligence Unit. The addition of this variable represents a way to purge our structural government spending shocks from the change in government spending already anticipated by economic agents, and hence to solve the problem known in the literature as fiscal foresight. Fiscal foresight is the phenomenon by which private agents, mainly due to legislative and implementation lags, can anticipate future movements in government spending. Failing to account for them in the identification of what are meant to be unanticipated government spending shocks may give rise to endogeneity and bias the results (see, e.g., Forni and Gambetti, 2010 and Leeper et al., 2013 among others for further details).

Fourth, we use as interaction term, $x_{t}$, the European Central Bank's shadow monetary policy rate developed by $\mathrm{Wu}$ and Xia (2017) (discussed in Section 1), which allows us to control for the overall monetary policy stance in the eurozone, and study the effects of a government spending shock at each percentile of the shadow rate distribution. Since this rate is available from $2004 \mathrm{Q} 3$ onward, for the very beginning of the sample, we complement it with the Main Refinancing Operations (MRO) rate, given that the two, until 2008, are virtually indistinguishable. To avoid potential reversed causality issues, we use the first lag of the shadow rate (i.e. $x_{t}=s r_{t-1}$ ), such that it is predetermined relative to the endogenous variables. It must be said, however, that the five factors do contain information on the contemporaneous monetary policy stance although, for our purposes, there is no need to explicitly identify a monetary policy shock. In particular, the informational dataset (see Appendix A.3) includes both money and credit quantity aggregates, and the harmonized government ten-year bond yield. The latter captures both expectations on monetary policy and market sentiment toward government debt dynamics. In a robustness check (Section 4) we also include the harmonized government ten-year bond yield explicitely in the panel VAR specification rather than in the computation of the factors.

Lastly, in order to account for international factors which may influence our variables of

CInternational Monetary Fund. Not for Redistribution 
interest, we add as exogenous variables also a set of U.S. variables, $z_{t-1}$, including the U.S. output gap, U.S. inflation and the U.S. shadow monetary policy rate developed by Wu and Xia (2016).

All the abovementioned modifications made to the traditional fiscal VAR specification are implemented within the IPVAR model. Therefore we label the model used in this paper as a factor-augmented interacted panel vector-autoregressive model purified of expectations (FAIPVAR-X).

\subsection{Inference, Identification and Computation of Cumulated Gov- ernment Spending Multipliers}

In line with Sá et al. (2014), we estimate the FAIPVAR-X model presented in equation (1) and compute cumulated government spending multipliers adopting the following seven steps:

1. Estimate the structural model equation by equation using ordinary least squares (OLS) and adopt a Bayesian strategy for inference utilizing an uninformative independent Normal-Wishart prior, which in turn uses a Montecarlo simulation to recover the posterior distribution of the structural parameters.

2. Make a draw of the posterior distribution and evaluate it at pre-specified values of the interaction term $x_{t}$.

3. Derive the model's corresponding reduced form, by pre-multiplying equation (1) by $B_{i, t}^{-1}$.

4. Use a sign restriction strategy to identify an unexpected government spending shock and compute the resulting impulse response functions (IRFs). More specifically, follow the same procedure of Sá et al. (2014), which in turn uses the algorithm developed by Rubio-Ramírez et al. (2010): after defining $V_{x}^{d}$ as the Cholesky decomposition of the reduced form variance-covariance matrix $\Sigma_{x}^{d}$, draw an orthonormal matrix $Q$ such that $Q^{\prime} Q=I$, from which it follows that $B^{d}=V_{x}^{d} Q$ and $\Sigma_{x}^{d}=B^{d^{\prime}} B^{d}=V_{x}^{d \prime} Q^{\prime} Q V_{x}^{d}$ where $d$ indicates a stable draw from the posterior distributions. ${ }^{6}$ To achieve identification, the impulse responses implied by $B^{d}$ have to satisfy the following restrictions: a government spending shock should raise $G D P_{i t}$ and $G_{i t}$ for at least four quarters (Table 1). ${ }^{7}$

\footnotetext{
${ }^{6}$ As in Cogley and Sargent (2005); Primiceri (2005); Sá et al. (2014), we discard any explosive draws from the unrestricted posterior.

${ }^{7}$ A Cholesky identification approach in the spirit of Blanchard and Perotti (2002) delivers similar results as long as the specification tackles the issue of limited information.
} 
Table 1: Sign Restrictions for Identifying the Government Spending Shock.

\begin{tabular}{ccc}
\hline Variable & Sign & Periods \\
\hline $\mathrm{G}_{\mathrm{it}}$ & + & 4 \\
$\mathrm{GDP}_{\mathrm{it}}$ & + & 4 \\
$\mathrm{~T}_{\mathrm{it}}$ & None & None \\
$F_{t}$ & None & None \\
\hline
\end{tabular}

5. Following Fry and Pagan (2011), use the median target approach to compute IRFs. For every 100 draws of the $Q$ matrix satisfying the sign restrictions, save that matrix implying the model with the impulse response functions closest to the median IRFs. ${ }^{8}$

6. Make 20,000 draws from the posterior distribution and discard the first 10,000 parameter draws as burn-in draws. For every remaining draw follow step 5. Among the 10,000 $Q$ matrices, consider again only the model producing the IRFs nearest to the median IRFs.

7. Compute cumulated government spending multipliers following the approach proposed by Gordon and Krenn (2010) and Ramey and Zubairy (2018). As already discussed, having normalized the variables of interest by real potential GDP, circumvents any concerns related to ex-post conversion. Thus, cumulated multipliers are computed simply as the ratio of discrete approximations of the integral of the median IRFs of real output and government purchases over a given time horizon $h=0,1, \ldots, H$ :

$$
\mathcal{M}_{H}=\frac{\sum_{h=0}^{H} d \mathrm{GDP}(h)}{\sum_{h=0}^{H} d \mathrm{G}(h)} .
$$

We account for parameter uncertainty by saving the 5th and 95th percentile of the distribution of the median as error bands. ${ }^{9}$

\footnotetext{
${ }^{8}$ Fry and Pagan (2011) claim that considering the median response as the point estimate of the exactly identified model may be inaccurate.

${ }^{9}$ We can distinguish between identification uncertainty and parameter uncertainty: the former reflects the lack of information we have about the properties of the structural shock; the latter accounts for the limited amount of data. While our identification strategy entails both identification and parameter uncertainty, we only show parameter uncertainty. This proves to be sufficient to establish whether there are differences among states (for further details see Paustian 2007; Sá et al. 2014).
} 


\section{Results}

This section reports all our baseline results. We start by showing, in Subsection 3.1, impulse responses of important macroeconomic variables to an unexpected shock to government spending, conditional on two shadow rate percentiles representative of two euro-area monetary policy regimes: normal times and ELB. Based on these impulse responses, in Subsection 3.2, we compute the associated cumulated government spending multipliers at various time horizons. In Subsection 3.3, we report the average multipliers for all shadow rate percentiles falling in the two monetary policy regimes. Finally, in Subsection 3.4, we inspect conditional correlations of the multipliers with the shadow rate and the business cycle.

\subsection{Impulse Responses Conditional on the Shadow Rate}

In this subsection we report impulse response functions (IRFs) of government spending, output, and net taxes - all in real terms - to an unexpected shock to government spending. One of the advantages of the FAIPVAR-X model is that it allows conditioning the IRFs on a specific percentile of the distribution of the shadow interest rate. In other words, we can interpret the IRFs as the dynamic reaction of macroeconomic variables to a shock to government spending occurring when the shadow rate takes a value corresponding to a given percentile of its own distribution.

For expositional ease we report IRFs conditional on two percentiles that are representative of two euro-area monetary policy regimes. We label the first regime normal times. This regime corresponds to the period between the beginning of our sample (2002q2) and the bankruptcy of Lehman Brothers (2008q3). In this period the shadow rate almost coincided with the official Eonia rate and the two were clearly positive (see Figure 1). We label the second regime $E L B$. This regime is comprised between $2012 q 4$, the quarter following ECB President Mario Draghi's famous 'Whatever it takes' speech, to the end of the sample (2017q4). During this period, the ECB lowered the monetary policy rate first to the ZLB and then to negative values. In other words, this period is characterized by a binding but time-varying ELB. The systematically negative shadow rate captures a series of unconventional measures including the Asset Purchase Program (APP) and forward guidance. ${ }^{10}$

The choice of regimes translates into a number of choices as far as shadow rate percentiles are concerned. We pick the 77 th percentile (2.75 percent; $2003 \mathrm{q} 2$ ) as a representative of the normal times regime, being the closest to the average shadow rate for that period $(2.82$

\footnotetext{
${ }^{10}$ We do not report IRFs for the intermediate period (2008q4-2012q3) as it is a hybrid period in which the monetary policy rate was quickly lowered but did not reach the ELB, while the shadow rate started to depart from the Eonia rate and fluctuated around zero, crossing the zero line three times. IRFs (available upon requests) are qualitatively very similar to those of normal times.
} 
Figure 2: Impulse Responses to a Government Spending Shock in Normal Times and at the ELB.
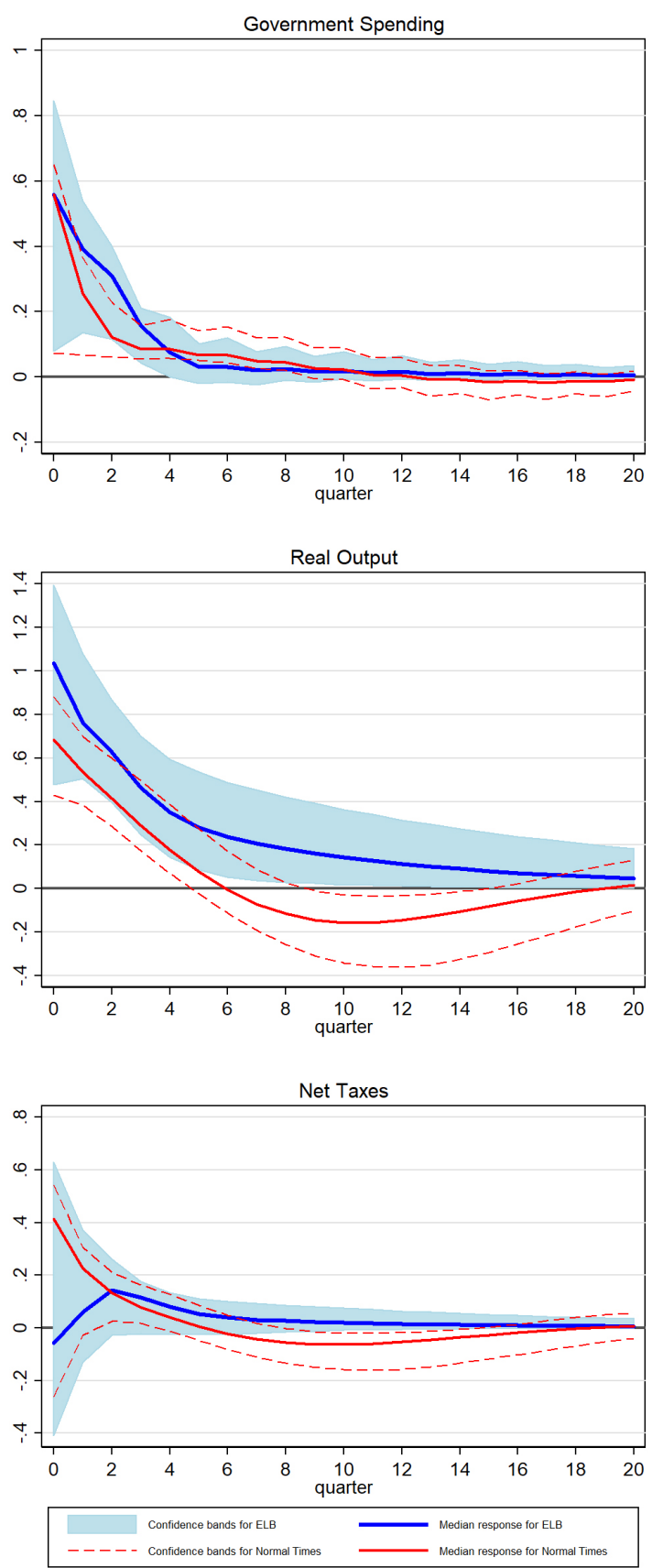

Notes: Impulse responses in percent to a shock of size one standard deviation. Bold lines represent median responses. Shadowed areas and dashed lines represent 90 percent confidence bands.

percent); and the 16 th percentile (-2.23 percent; 2015q3) as a representative of the ELB regime, again being the closest to the average shadow rate for that period (-2.29 percent).

Figure 2 contrasts the IRFs for the normal times regime with those for the $E L B$ regime. 
Table 2: Cumulated Government Spending Multipliers Conditional on Two Levels of the Shadow Rate Representative of Normal Times and the ELB.

\begin{tabular}{|c|c|c|c|}
\hline Horizon & $H$ & $\begin{array}{c}\left.\mathcal{M}_{H}\right|_{\text {pctl }(s r)} \\
\text { Normal Times } \\
\operatorname{pctl}(s r)=77\end{array}$ & $\begin{array}{c}\left.\mathcal{M}_{H}\right|_{\text {pctl }(s r)} \\
\text { Effective Lower Bound } \\
\operatorname{pctl}(s r)=16\end{array}$ \\
\hline 1 year & 4 & 1,90 & 2,17 \\
\hline 2 years & 8 & 1,48 & 2,59 \\
\hline 3 years & 12 & 0,99 & 2,82 \\
\hline 4 years & 16 & 0,74 & 2,96 \\
\hline 5 years & 20 & 0,75 & 3,05 \\
\hline
\end{tabular}

Notes: Multipliers computed as in Equation (4). Percentiles refer to chosen percentiles of the shadow rate. The 77th percentile is representative of the normal times regime. The 16th percentile is representative of the $E L B$ regime. $H$ identifies the number of quarters after the shock.

A few remarks are in order. First, in all cases a shock to government spending keeps spending itself persistently above baseline and it takes about ten quarters to die out. Second, output and net taxes respond positively to the shock, although the credible set of responses of net taxes often includes zero. Third, comparing the results for normal times against those for $E L B$ unveils that, when the economy is at the ELB, the responses of output are for the most part larger, with their confidence bands not overlapping in several quarters after the occurrence of the shock (quarters 8-14).

\subsection{Cumulated Government Spending Multipliers Conditional on Shadow Rate Levels}

Based on these impulse responses, we can compute the cumulated government spending multipliers at several time horizons explained in Subsection 2.3. Results are reported in Table 2. Both in the short and the medium term the multiplier is systematically higher when the economy is at the ELB, relative to normal times. Importantly though, while the one-year multiplier is of comparable magnitude, there is a stark difference in the dynamics of the multiplier across the two regimes as times goes by. In normal times, the multiplier decays so that in the medium term (three to five years) the magnitude is around or less than 1. At the $E L B$, the magnitude of the multiplier increases up to 3.

A fair question is whether the difference between the two sets of multiplier is statistically significant. Bayesian inference does not allow us to construct a test as in the frequentist approach. Therefore we follow an approach analogous to Caggiano et al. (2015). We compute empirical distributions of the differences computed as multipliers conditional on the level of the shadow rate representative of the $E L B$ regime $\left(\left.\mathcal{M}_{H}\right|_{\mathrm{pctl}(s r)=16}\right)$ minus multipli- 
Table 3: Average Cumulated Government Spending Multipliers in Normal Times and at the ELB.

\begin{tabular}{lccc}
\hline Horizon & & $\begin{array}{c}\text { mean }\left(\left.\mathcal{M}_{H}\right|_{\mathrm{pctl}(s r)}\right) \\
\text { Normal Times }\end{array}$ & $\begin{array}{c}\text { mean }\left(\left.\mathcal{M}_{H}\right|_{\mathrm{pctl}(s r)}\right) \\
\text { Effective Lower Bound }\end{array}$ \\
\hline 1 year & $H$ & 2,13 & 2,10 \\
2 years & 8 & 1,57 & 2,44 \\
3 years & 12 & 1,08 & 2,58 \\
4 years & 16 & 0,79 & 2,73 \\
5 years & 20 & 0,64 & 2,83 \\
\hline
\end{tabular}

Notes: Multipliers are computed as in Equation (4) for each percentile of the shadow rate distribution and averaged across the percentiles belonging to the normal times and the ELB regime. $H$ identifies the number of quarters after the shock.

ers conditional on the level of the shadow rate representative of the normal times regime $\left.\mathcal{M}_{H}\right|_{\text {pctl(sr)=77 }}$ and verify whether a very large part of the distributions include zero or not. In particular, for each of the 10,000 parameter draws from the posterior distribution, we compute the multipliers as in Equation (4), evaluate them at the two percentiles of interest, and compute the difference between the two. Figure 3 plots the distributions of the difference between the two multipliers cumulated at various time horizons together with 90 percent confidence bands. It turns out that, from horizon three to five, 90 percent of these distribution do not include zero, indicating that the difference between the two multiplier is positive with high probability.

\subsection{Average Cumulated Government Spending Multipliers in Nor- mal Times and the ELB}

With the FAIPVAR-X model, IRFs can be computed conditional on all percentiles of the shadow rate distribution, which can be easily reconducted to a specific quarter in the history of the EMU. This allows us to compute time series of the cumulated government spending multipliers. Table 3 reports the average of these time series over the periods we identify as normal times and ELB. This way we can check whether the results based on the two specific percentiles representative of the two periods, hold also on average. It turns out that using average multipliers does not alter our conclusions. One-year multipliers are still very similar across the two regimes while, at longer time horizons, multipliers still diverge across regimes as the horizon increases, with the normal-times multiplier falling below 1 and the $E L B$ multiplier being much larger in the medium term. Also from a quantitative viewpoint estimates are similar, with the three-year multiplier around one in normal times and 2.6 at 
Figure 3: Distributions of Differences in Cumulated Government Spending Multipliers between Two Levels of the Shadow Rate Representative of Normal Times and the ELB.

(a) One year $(H=4)$

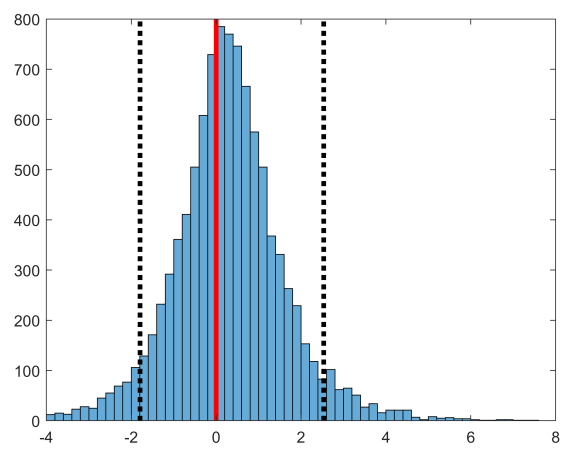

(c) Three years $(H=12)$

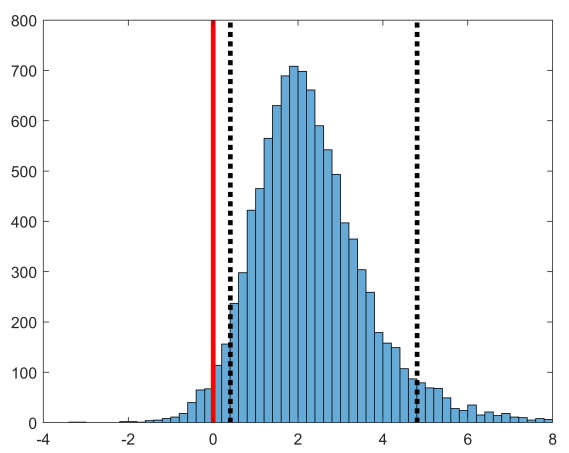

(b) Two years $(H=8)$

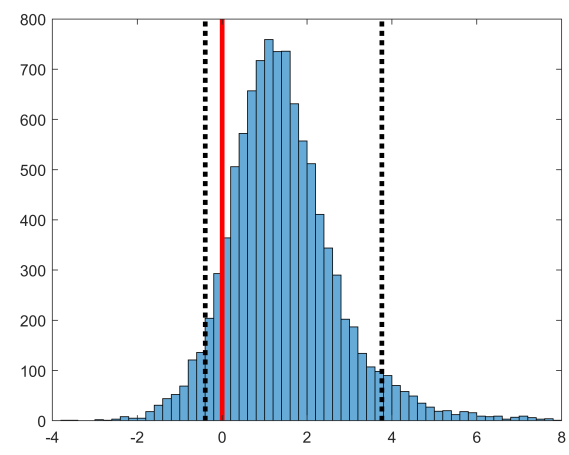

(d) Four years $(H=16)$

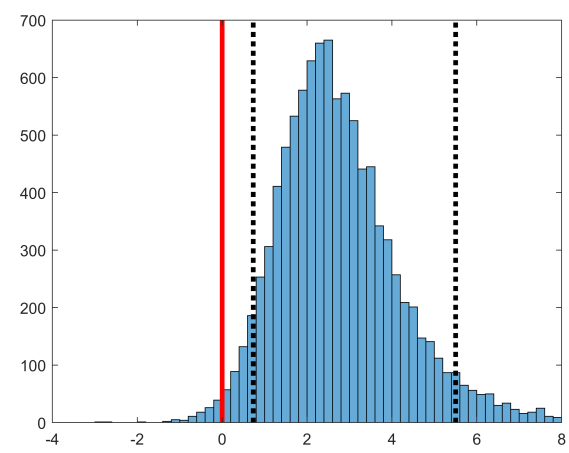

(e) Five years $(H=20)$

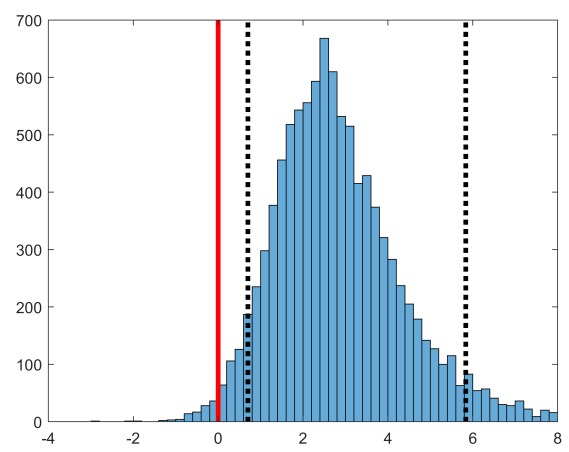

Notes: Empirical distributions of the differences computed as multipliers conditional on the level of the shadow rate representative of the ELB regime $\left(\left.\mathcal{M}_{H}\right|_{\text {pctl(sr })=16}\right)$ minus multipliers conditional on the level of the shadow rate representative of the normal times regime $\left.\mathcal{M}_{H}\right|_{\text {pctl(sr)=77. Multipliers are computed as }}$ in Equation (4) for each of the 10,000 parameter draws from the posterior distribution. Vertical dotted lines represent the 5 th and the 95 th percentiles of the distribution of differences. $H$ identifies the number of quarters after the shock. 
the $E L B$, and the five-year multiplier 0.6 in normal times and 2.8 at the ELB.

Also in the context of average multipliers we construct distributions of the difference between average multipliers analogous to those constructed on the multipliers conditional on specific shadow rate percentiles (reported on Subsection 3.2). In this case, for each of the 10,000 parameter draws from the posterior distribution, we compute the average multiplier for the two regimes and save the difference between the two. Figure 4 plots the distributions of these differences with 90 percent confidence bands, at various time horizons. The interpretation of each subplot is identical to that of Figure 3. It turns out that the difference between average multipliers is non-zero with 90 percent probability at horizons 2 , 3 and 4 years (on the margin of significance at year 2). We cannot exclude zero at horizons 1 and 5 years.

Taken together, Subsections 3.2 and 3.3 suggest that in the EA (i) the difference between the size of the one-year government spending multiplier at the ELB and in normal times is neither economically nor statistically significant; (ii) this difference increases, and its distribution is largely away from zero, at longer time horizons; in the medium-term (say 3 years) while the multiplier in normal times is about 1, at the ELB it exceeds 2.5.

These results are in line with a strand of the theoretical (DSGE) literature that claims the fiscal multiplier to be much higher at the ZLB (Christiano et al., 2011; Coenen et al., 2012; Davig and Leeper, 2011; Eggertsson, 2010; Kilponen et al., 2015; Woodford, 2011, among others). ${ }^{11}$ However, it has to be stressed that while in DSGE models it is possible to quantify the effects of the ZLB in isolation, in the data this task is much more difficult. In fact, when the policy rate reached the ELB, monetary policy did not simply cease to operate; it continued to function in an unconventional manner. By conditioning the computation of the multiplier on the shadow monetary policy rate, we simultaneously capture not only the

effects of the time-varying ELB in the EA, but also those of all unconventional monetary policies.

\subsection{Correlations of the Multiplier with the Shadow Rate and the Business Cycle}

There is a strand of the literature that finds government spending multipliers to be dependent on the business cycle in advanced economies, and in particular to be higher in recessions relative to expansions (see Auerbach and Gorodnichenko, 2012, 2013; Batini et al., 2012, among others). ${ }^{12}$ Given that the shadow rate typically becomes smaller when the economy

\footnotetext{
${ }^{11}$ Note that in DSGE models the ELB always coincides with the ZLB.

${ }^{12}$ Ramey and Zubairy (2018) do not confirm this result for the U.S. using a longer times series when they construct the fiscal multipliers as we do (see Subsection 2.3).
} 
Figure 4: Distributions of Differences in Average Cumulated Government Spending Multipliers between Normal Times and the ELB.

(a) One year $(H=4)$

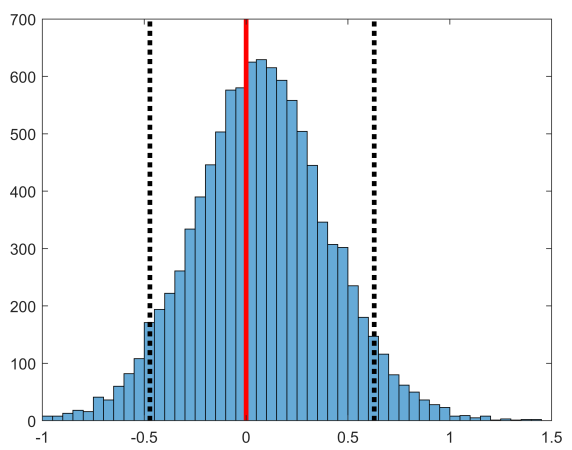

(c) Three years $(H=12)$

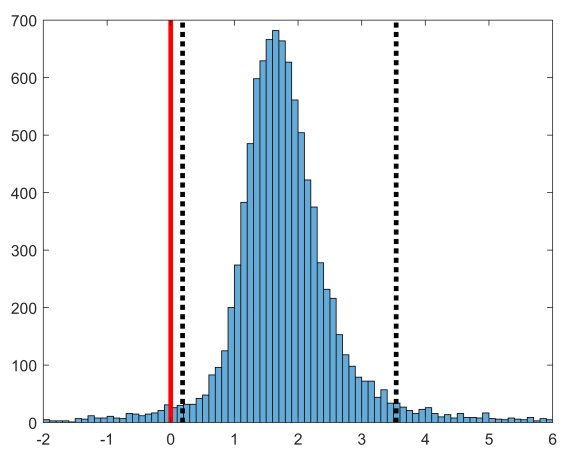

(b) Two years $(H=8)$

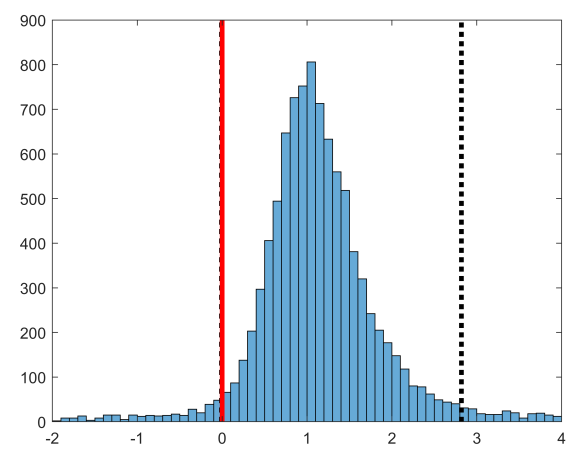

(d) Four years $(H=16)$

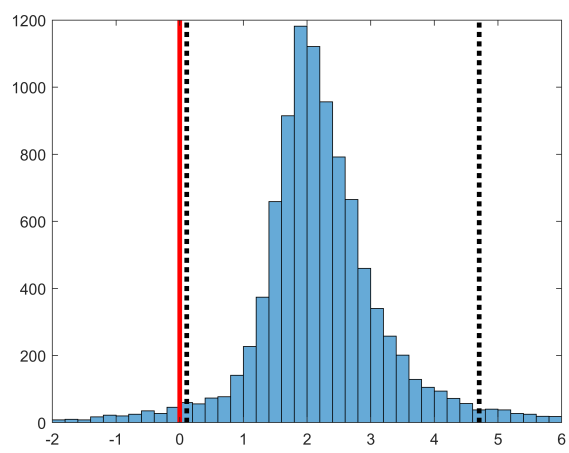

(e) Five years $(H=20)$

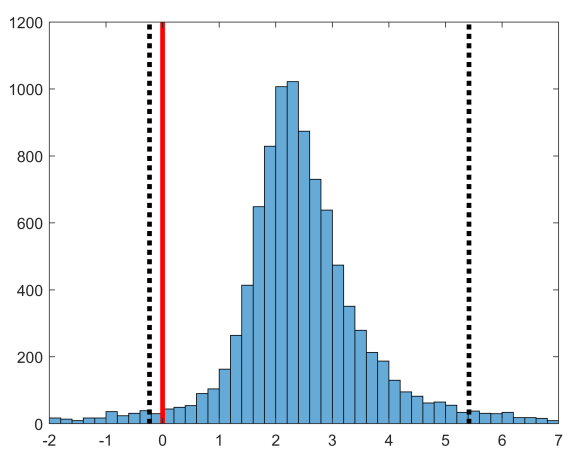

Notes: Empirical distributions of the differences computed as average multipliers in the ELB regime minus average multipliers in the normal times regime. Multipliers are computed as in Equation (4) for each of the 10,000 parameter draws from the posterior distribution. Vertical dotted lines represents the 5th and the 95th percentiles of the distribution of differences. $H$ identifies the number of quarters after the shock.

is below trend and viceversa, in this subsection we verify that the correlation between the fiscal multiplier and the shadow rate survives also when we control for the state of the 
Table 4: Conditional Correlations of Cumulated Multipliers with the Lagged Shadow Rate and the Lagged Business Cycle.

\begin{tabular}{lccc}
\hline Horizon & $H$ & $\operatorname{corr}\left(\hat{\varepsilon}_{t}^{\mathcal{M}_{H} \mid b c}, s r_{t-1}\right)$ & $\operatorname{corr}\left(\hat{\varepsilon}_{t}^{\mathcal{M}_{H} \mid s r}, b c_{t-1}\right)$ \\
\hline 1 year & 4 & 0,2044 & $-0,1822$ \\
& & $(0,1383)$ & $(0,1873)$ \\
2 years & 8 & $-0,7200$ & $-0,3508$ \\
& & $(0,0000)$ & $(0,0093)$ \\
3 years & 12 & $-0,8290$ & $-0,4052$ \\
& \multirow{2}{*}{$\begin{array}{l}4 \\
\text { years }\end{array}$} & $(0,0000)$ & $(0,0024)$ \\
& \multirow{2}{*}{5 years } & $-0,8389$ & $-0,3326$ \\
& 20 & $(0,0000)$ & $(0,0140)$ \\
& & $-0,8258$ & $-0,2814$ \\
\end{tabular}

Notes: Conditional correlations are obtained running two auxiliary regressions and computing the correlation coefficients between the residuals of these regressions and the variables of interest. The first regresses the cumulated multiplier on a constant and the lagged business cycle indicator. The correlation is computed between the residuals of this regression and the lagged shadow rate. The second regresses the cumulated multiplier on a constant and the lagged shadow rate. The correlation is computed between the residuals of this regression and the lagged business cycle indicator. These computations are replicated at different horizons $H$ for the cumulated multipliers. P-values are in parentheses.

business cycle.

The FAIPVAR-X model, by conditioning on the various percentiles of the shadow rate, allows us to compute time series of multipliers. Thus, we compute the correlation between the cumulated multipliers and the lagged shadow rate, conditional on a lagged business cycle indicator (see Appendix A for details). In practice, we run the following regression:

$$
\mathcal{M}_{H, t}=b_{0} c+b_{1} b c_{t-1}+\varepsilon_{t}^{\mathcal{M}_{H} \mid b c}
$$

where $\mathcal{M}_{H, t}$ is the series of multipliers at horizon $H, c$ is a constant, $b c_{t}$ is the business cycle indicator, $b_{0}$ and $b_{1}$ are regression coefficients, and $\varepsilon_{t}^{\mathcal{M}_{H} \mid b c}$ is the error term. From this regression, we save the residuals, $\hat{\varepsilon}_{t}^{\mathcal{M}_{H} \mid b c}$, and we compute the correlation coefficient with the lagged shadow rate $\left(s r_{t-1}\right)$. Results are reported in Table 4 . While statistically insignificant at a one-year horizon, the conditional correlation is strongly negative and significant at all other horizons. This finding gives assurance that the association of the shadow rate with the size of the government spending multiplier at horizons greater than one is autonomous from that of the business cycle. Results based on contemporaneous variables are virtually the same and reported in Appendix B (Table B.1).

Nonetheless, EA data still give support to the view that the multiplier is larger in peri- 
ods of economic slack. We arrive at this conclusion by running a second regression of the multiplier on a constant and the lagged shadow rate:

$$
\mathcal{M}_{H, t}=b_{0} c+b_{1} s r_{t-1}+\varepsilon_{t}^{\mathcal{M}_{H} \mid s r}
$$

and by computing the correlation between the residuals of this regression, $\hat{\varepsilon}_{t}^{\mathcal{M}_{H} \mid b c}$, and the lagged business cycle indicator. This correlation coefficient is negative and statistically different from zero at a 1 percent level at all time horizons except for the first year. In other words, after controlling for the level of the shadow rate, the multiplier is still negatively correlated with the business cycle. Also in this case, results based on contemporaneous variables, reported in Appendix B (Table B.1), are virtually the same. In sum, both the shadow rate and the state of the business cycle have an autonomous correlation with the size of the fiscal multiplier in the eurozone.

\section{Robustness Checks}

In this section we present the results of three robustness checks addressing issues commonly discussed in the literature, which may be applicable also to the analysis presented in this paper:

1. Sign restrictions imposed for two periods. To produce the baseline results, we applied positive sign restrictions to the IRFs of real GDP and government spending for four quarters, with the purpose of identifying a temporary government spending shock, given that governments' budgets normally cover a year. Given that the literature has shown that results may be sensitive to the choice of number of quarters for which restrictions are imposed, we check the robustness of our results to imposing the minimum set of restrictions useful to reach identification. In our case this translates into two quarters. In fact, we verified that imposing restrictions for only one quarter would lead to the so-called multiple shocks problem (Fry and Pagan, 2011). This issue arises where there is not enough information to discriminate among shocks and, in the same rotation matrix, there are more than one shock (more than one column) that potentially qualify as government spending shocks because they produce the right set of signs.

2. Lag structure of two quarters. Given that the FAIPVAR-X model requires the estimation of a large number of parameters, for the sake of parsimony, we produce the baseline results with a uniform lag structure of one quarter. Bearing in mind that 
Table 5: Robustness Checks on the Average Cumulated Government Spending Multipliers in Normal Times and at the ELB.

\begin{tabular}{lc|cc|cc|cc}
\hline & \multicolumn{6}{c}{ mean $\left(\left.\mathcal{M}_{H}\right|_{\mathrm{pct}(s r)}\right)$} \\
\cline { 3 - 7 } & & \multicolumn{2}{c}{$\begin{array}{c}\text { Sign restrictions } \\
\text { imposed for 2 quarters }\end{array}$} & \multicolumn{2}{c}{ Lag structure of } & \multicolumn{2}{c}{$\begin{array}{c}\text { Including 10-year } \\
\text { gov. bond yields }\end{array}$} \\
\hline Horizon & $H$ & Normal Times & ELB & Normal Times & ELB & Normal Times & ELB \\
\hline 1 year & 4 & 1,71 & 1,70 & 2,22 & 2,91 & 2,02 & 1,70 \\
2 years & 8 & 1,50 & 1,91 & 1,62 & 3,01 & 1,70 & 1,68 \\
3 years & 12 & 1,15 & 2,03 & 1,20 & 2,83 & 1,39 & 1,63 \\
4 years & 16 & 0,93 & 2,10 & 1,12 & 2,85 & 1,15 & 1,63 \\
5 years & 20 & 0,82 & 2,16 & 1,09 & 2,84 & 0,96 & 1,63 \\
\hline
\end{tabular}

Notes: Multipliers are computed as in Equation (4) for each percentile of the shadow rate distribution and averaged across the percentiles belonging to the normal times and the ELB regime. $H$ identifies the number of quarters after the shock.

the use of a long lag structure would not be feasible as we would run out of degrees of freedom, we check whether results are robust to the use of a lag structure of two quarters $(L=2)$.

3. Including 10-year government bond yields. It is possible that market expectations on monetary policy and toward government debt dynamics may have an impact on the size of the fiscal multiplier. Our approach deals with such issues by augmenting the VAR specification with factors extracted from a large set of macroeconomic indicators. Nonetheless, here we replicate our results after including the harmonized government ten-year bond yield explicitly in the panel VAR specification rather than in the computation of the factors, while still including factors extracted using the remaining variables.

As shown in Table 5, subjecting our estimates to these robustness checks leads to multipliers in the same order of magnitude as those reported in the baseline results. Importantly, deviating from the baseline set of estimates does not alter the fact that while the average one-year multiplier is very similar across the normal times and the ELB regimes; as the time horizon increases, multipliers diverge across the two regimes with the $E L B$ regime displaying substantially higher multipliers in the medium run.

Next, we also assess the robustness of the results on the distribution of the difference of the multipliers across regimes for each estimation variant. Table 6 reports the the 5th and 95th percentiles of the distributions of the difference between average cumulated government spending multipliers across normal times and the ELB. The interpretation is the same as that of Figure 4: if the confidence interval excludes zero, then the difference is non-zero 
Table 6: Robustness Checks on the Distributions of Differences between Average Cumulated Government Spending Multipliers between Normal Times and the ELB.

\begin{tabular}{lc|cc|cc|cc}
\hline & \multicolumn{5}{c}{$\begin{array}{c}\text { Distributions of Difference in Average Cumulated Government } \\
\text { Spending Multipliers in Normal Times and the ELB }\end{array}$} \\
\cline { 3 - 7 } & & \multicolumn{2}{c}{$\begin{array}{c}\text { Sign restrictions } \\
\text { imposed for 2 quarters }\end{array}$} & \multicolumn{2}{c}{$\begin{array}{c}\text { Lag structure of } \\
2\end{array}$} & \multicolumn{2}{c}{$\begin{array}{c}\text { Including 10-year } \\
\text { gov. bond yields }\end{array}$} \\
\hline Horizon & $H$ & 5 th pctl & 95 th pctl & 5th pctl & 95th pctl & 5th pctl & 95th pctl \\
\hline 1 year & 4 & $-0,50$ & 0,38 & 0,19 & 1,23 & $-0,60$ & 0,49 \\
2 years & 8 & $-0,30$ & 1,43 & 0,73 & 2,08 & $-0,31$ & 1,09 \\
3 years & 12 & 0,08 & 2,18 & 0,36 & 2,77 & $-0,07$ & 1,47 \\
4 years & 16 & 0,17 & 2,77 & $-1,55$ & 4,20 & 0,08 & 1,84 \\
5 years & 20 & 0,09 & 3,28 & $-1,51$ & 3,88 & 0,28 & 2,22 \\
\hline
\end{tabular}

Notes: Empirical distributions of the differences computed as average multipliers in the ELB regime minus average multipliers in the normal times regime. Multipliers are computed as in Equation (4) for each of the 10,000 parameter draws from the posterior distribution. In the table we report the 5 th and the 95th percentiles of the distribution of differences. $H$ identifies the number of quarters after the shock.

with probability 90 percent. Across all estimation variants (including the baseline reported in Subection 3.3), at an intermediate horizon (3 and/or 4 years) the difference between multipliers in the two regimes is non-zero with probability 90 percent.

Finally, we check whether the conditional correlations of the cumulated multipliers with one lag of the shadow rate and one lag of the business cycle indicator survive the three estimation variants. Results are reported in Table 7. Both correlations are strong and for the most part statistically significant. In Appendix B we show that using contemporaneous quarters of the shadow rate and the business cycle leaves findings virtually unchanged.

\section{Conclusions}

Policymakers are always confronted with the practical challenge of having to make assumptions on fiscal multipliers when designing macroeconomic adjustment scenarios and, especially in periods of low aggregate demand, the fiscal multiplier is typically at the forefront of the macroeconomic debate. Academics have often questioned whether the multiplier is indeed a multiplier, that is, whether it is greater or smaller than one. Therefore, many theoretical and empirical contributions proposed models and empirical strategies to estimate its size. The economic profession is still far from achieving a consensus on actual estimates. However, there is at least a convergence on the idea that the size of the multiplier heavily depends on the macroeconomic policies prevailing when fiscal measures are implemented. 
Table 7: Robustness Checks on Conditional Correlations of Cumulated Multipliers with the Lagged Shadow Rate and the Lagged Business Cycle.

\begin{tabular}{|c|c|c|c|c|c|c|c|}
\hline \multirow{2}{*}{ Horizon } & \multicolumn{3}{|c|}{$\begin{array}{c}\text { Sign restrictions } \\
\text { imposed for } 2 \text { quarters }\end{array}$} & \multicolumn{2}{|c|}{$\begin{array}{l}\text { Lag structure of } \\
2 \text { quarters }\end{array}$} & \multicolumn{2}{|c|}{$\begin{array}{l}\text { Including 10-year } \\
\text { gov. bond yields }\end{array}$} \\
\hline & $H$ & $\hat{\varepsilon}_{t}^{\mathcal{M}_{H} \mid b c}, s r_{t-1}$ & $\hat{\varepsilon}_{t}^{\mathcal{M}_{H} \mid s r}, b c_{t-1}$ & $\hat{\varepsilon}_{t}^{\mathcal{M}_{H} \mid b c}, s r_{t-1}$ & $\hat{\varepsilon}_{t}^{\mathcal{M}_{H} \mid s r}, b c_{t-1}$ & $\hat{\varepsilon}_{t}^{\mathcal{M}_{H} \mid b c}, s r_{t-1}$ & $\hat{\varepsilon}_{t}^{\mathcal{M}_{H} \mid s r}, b c_{t-1}$ \\
\hline \multirow[t]{2}{*}{1 year } & 4 & 0,1815 & $-0,4068$ & $-0,4369$ & $-0,3431$ & 0,5137 & $-0,4418$ \\
\hline & & $(0,1890)$ & $(0,0023)$ & $(0,0010)$ & $(0,0111)$ & $(0,0001)$ & $(0,0008)$ \\
\hline \multirow[t]{2}{*}{2 years } & 8 & $-0,5811$ & $-0,5592$ & $-0,7836$ & $-0,2283$ & 0,1890 & $-0,5344$ \\
\hline & & $(0,0000)$ & $(0,0000)$ & $(0,0000)$ & $(0,0968)$ & $(0,1710)$ & $(0,0000)$ \\
\hline \multirow[t]{2}{*}{3 years } & 12 & $-0,8121$ & $-0,5948$ & $-0,7896$ & $-0,2828$ & $-0,1497$ & $-0,5642$ \\
\hline & & $(0,0000)$ & $(0,0000)$ & $(0,0000)$ & $(0,0383)$ & $(0,2800)$ & $(0,0000)$ \\
\hline \multirow[t]{2}{*}{4 years } & 16 & $-0,8092$ & $-0,5563$ & $-0,7467$ & $-0,2007$ & $-0,3429$ & $-0,5553$ \\
\hline & & $(0,0000)$ & $(0,0000)$ & $(0,0000)$ & $(0,1456)$ & $(0,0111)$ & $(0,0000)$ \\
\hline \multirow[t]{2}{*}{5 years } & 20 & $-0,7952$ & $-0,5041$ & $-0,6892$ & $-0,1753$ & $-0,4140$ & $-0,5329$ \\
\hline & & $(0,0000)$ & $(0,0001)$ & $(0,0000)$ & $(0,2047)$ & $(0,0019)$ & $(0,0000)$ \\
\hline
\end{tabular}

Notes: Conditional correlations are obtained running two auxiliary regressions and computing the correlation coefficients between the residuals of these regressions and the variables of interest. The first regresses the cumulated multiplier on a constant and the lagged business cycle indicator. The correlation is computed between the residuals of this regression and the lagged shadow rate. The second regresses the cumulated multiplier on a constant and the lagged shadow rate. The correlation is computed between the residuals of this regression and the lagged business cycle indicator. These computations are replicated at different horizons $H$ for the cumulated multipliers. P-values are in parentheses.

This paper focuses on one aspect of macroeconomic policy that became one of the defining features of the period that followed the GFC in most advanced economies: the ELB. Because of the ELB, many argued that fiscal authorities needed to do more to provide the necessary stimulus to mitigate output and job losses. Central banks, on their part, had to become creative in how to conduct monetary policy, often exploring unchartered territories. Macroeconomists started to argue that the size of the fiscal multiplier would likely be different when the economy is at the ELB. This assertion was initially only circumstantiated using theoretical models, as unfortunately there were not enough data points to conduct formal empirical estimations.

Ten years after the beginning of the GFC, both data and econometric tools allow us to explore this question empirically. We focus on the EA because, besides being one of the largest advanced economy with no available estimates of the fiscal multiplier at the ELB, it is a very interesting laboratory for this research question. The ECB made the ELB timevarying, pushing the monetary policy rate into the negative territory and then complemented it with quantitative easing and forward guidance. In addition, the eurozone experienced both fiscal stimulus measures following the GFC, and austerity to deal with the sovereign debt 
crisis, in sum substantial discretionary fiscal shocks.

Cognizant of the challenges of isolating the effect of the ELB on the computation of the fiscal multiplier, we prefer to take an approach that controls for the overall monetary policy stance, including the time-varying ELB. In other words, we condition the calculation of the government spending multiplier on a shadow monetary policy rate. The most recent literature highlighted many econometric problems that should be taken into consideration when dealing with fiscal multipliers. We use these lessons to devise our econometric approach, the FAIPVAR-X model, which tackles problems of limited information and fiscal foresight, among other matters.

Our results agree with those theoretical predictions pointing to a larger size of the government spending multiplier at the ELB versus so-called normal times, albeit with some qualifications. Following the most recent literature, we compute cumulated multipliers at various time horizons. In the short run (one year), whether the fiscal shock occurs when the economy is at the ELB or in normal times does not seem to matter for the size of the multiplier. However, as the time horizon increases, multipliers diverge across the two regimes. In the medium run (three years), the average multiplier is about 1 in normal times and between 1.6 and 2.8 at the ELB, depending on the specification. The difference between the two multipliers is distributed largely away from zero. The FAIPVAR-X model allows us to compute a multiplier for all percentiles of the shadow rate. It turns out that the multiplier is inversely correlated with the level of the shadow monetary policy rate. Lastly, we verify that EA data are in line with the view that the multiplier is larger in periods of economic slack. Importantly, we show that the shadow rate and the state of the business cycle are autonomously correlated with its size.

Our results are important at least for two reasons. First, using data of a large advanced economy, they add empirical backing to a strand of theoretical contributions. The second reason is perhaps more important from a policy perspective. At a time of phasing out of the ECB's asset purchase program and prospective normalization of monetary policy, this paper may provide an educated guess of the multiplier policymakers in the EA should use in the forthcoming normal times. Our estimates suggest a medium-term value of about 1 . 


\section{References}

Aruoba, S. B., P. Cuba-Borda, and F. Schorfheide (2017). Macroeconomic Dynamics near the ZLB: A Tale of Two Countries. The Review of Economic Studies 85(1), 87-118.

Auerbach, A. J. and Y. Gorodnichenko (2012). Measuring the Output Responses to Fiscal Policy. American Economic Journal: Economic Policy 4(2), 1-27.

Auerbach, A. J. and Y. Gorodnichenko (2013). Fiscal Multipliers in Recession and Expansion. In A. Alesina and F. Giavazzi (Eds.), Fiscal Policy after the Financial Crisis, pp. 63-98. University of Chicago Press.

Bai, J. and S. Ng (2007). Determining the Number of Primitive Shocks in Factor Models. Journal of Business and Economic Statistics 25(1), 52-60.

Batini, N., G. Callegari, and G. Melina (2012). Successful Austerity in the United States, Europe and Japan. IMF Working Paper 190.

Bernanke, B. S., J. Boivin, and P. S. Eliasz (2005). Measuring the Effects of Monetary Policy: a Factoraugmented Vector Autoregressive (FAVAR) approach. The Quarterly Journal of Economics 120, 387-422.

Bi, H., W. Shen, and S.-C. S. Yang (2016). Debt-dependent effects of fiscal expansions. European Economic Review 88, 142 - 157. SI: The Post-Crisis Slump.

Blanchard, O. J. and R. Perotti (2002). An Empirical Characterization of the Dynamic Effects of Changes in Government Spending and Taxes on Output. Quarterly Journal of Economics 117(4), 1329-1368.

Bonam, D., J. de Haan, and B. Soederhuizen (2017, July). The effects of fiscal policy at the effective lower bound. DNB Working Papers 565, Netherlands Central Bank, Research Department.

Braun, R. A., L. M. Körber, and Y. Waki (2013). Small and Orthodox Fiscal Multipliers at the Zero Lower Bound. FRB Atlanta Working Paper No. 2013-13.

Caggiano, G., E. Castelnuovo, V. Colombo, and G. Nodari (2015). Estimating Fiscal Multipliers: News From A Non-linear World. Economic Journal 125(584), 746-776.

Canova, F. and M. Ciccarelli (2013). Panel Vector Autoregressive Models: A Survey. In VAR Models in Macroeconomics-New Developments and Applications: Essays in Honor of Christopher A. Sims, pp. 205-246. Emerald Group Publishing Limited.

Christiano, L., M. Eichenbaum, and S. Rebelo (2011). When Is the Government Spending Multiplier Large? Journal of Political Economy 119(1), 78-121.

Coenen, G., C. J. Erceg, C. Freedman, D. Furceri, M. Kumhof, R. Lalonde, D. Laxton, J. Lindé, A. Mourougane, D. Muir, S. Mursula, C. de Resende, J. Roberts, W. Roeger, S. Snudden, M. Trabandt, and J. in't Veld (2012). Effects of Fiscal Stimulus in Structural Models. American Economic Journal: Macroeconomics 4(1), 22-68.

Cogley, T. and T. J. Sargent (2005). Drift and Volatilities: Monetary Policies and Outcomes in the Post WWII U.S. Review of Economic Dynamics 8, 262-302.

Cwik, T. and V. Wieland (2011). Keynesian Government Spending Multipliers and Spillovers in the Euro Area. Economic Policy 26(67), 493-549.

Davig, T. and E. M. Leeper (2011). Monetary-Fiscal Policy Interactions and Fiscal Stimulus. European Economic Review 55(2), 211-227.

Dickey, D. A. and W. A. Fuller (1979). Distribution of the Estimators for Autoregressive Time Series With a Unit Root. Journal of the American Statistical Association 74(366), 
427-431.

Eggertsson, G. B. (2010). What Fiscal Policy is Effective at Zero Interest Rates? In D. Acemoglu and M. Woodford (Eds.), NBER Macroeconomics Annual, Volume 25, pp. 59-112. Cambridge, MA: MIT Press.

Forni, M. and L. Gambetti (2010, May). Fiscal Foresight and the Effects of Goverment Spending. CEPR Discussion Papers 7840, C.E.P.R. Discussion Papers.

Forni, M., D. Giannone, M. Lippi, and L. Reichlin (2009). Opening the Black Box: Structural Factor Models with Large Cross Sections. Econometric Theory 25, 1319-1347.

Fragetta, M. and E. Gasteiger (2014). Fiscal Foresight, Limited Information and the Effects of Government Spending Shocks. Oxford Bulletin of Economics and Statistics 76(5), 667692.

Fry, R. and A. Pagan (2011). Sign Restrictions in Structural Vector Autoregressions: A Critical Review. Journal of Economic Literature 49(4), 938-960.

Gordon, R. J. and R. Krenn (2010). The End of the Great Depression 1939-41: Policy Contributions and Fiscal Multipliers. NBER Working Paper 16380, National Bureau of Economic Research.

Hamilton, J. D. (2018). Why You Should Never Use the Hodrick-Prescott Filter. Review of Economics and Statistics 100(5), 831-843.

Ilzetzki, E., E. G. Mendoza, and C. A. Végh (2013). How Big (Small?) Are Fiscal Multipliers? Journal of Monetary Economics 60(2), 239-254.

Kilponen, J., M. Pisani, S. Schmidt, V. Corbo, T. Hlédik, J. Hollmayr, S. Hurtado, P. Júlio, D. Kulikov, M. Lemoine, M. Lozej, H. Lundvall, J. F. Maria, B. Micallef, D. Papageorgiou, J. Rysanek, D. Sideris, C. Thomas, and G. De Walque (2015). Comparing Fiscal Multipliers Across Models and Countries in Europe. Working Paper Series 1760, European Central Bank.

Kirchner, M., J. Cimadomo, and S. Hauptmeier (2010). Transmission of Government Spending Shocks in the Euro Area: Time Variation and Driving Forces. Working Paper Series 1219, European Central Bank.

Kwiatkowski, D., P. C. B. Phillips, P. Schmidt, and Y. Shin (1992). Testing the Null Hypothesis of Stationarity Against the Alternative of a Unit Root: How Sure Are We That Economic Time Series Have a Unit Root? Journal of Econometrics 54(1-3), 159178.

Leeper, E. M., T. B. Walker, and S. C. S. Yang (2013). Fiscal Foresight and Information Flows. Econometrica 81(3), 1115-1145.

Mertens, K. and M. O. Ravn (2014). Fiscal Policy in an Expectations Driven Liquidity Trap. Review of Economic Studies 81(4), 1637-1667.

Nickel, C. and A. Tudyka (2014). Fiscal stimulus in times of high debt: Reconsidering multipliers and twin deficits. Journal of Money, Credit and Banking 46 (7), 1313-1344.

Paustian, M. (2007). Assessing Sign Restrictions. The BE Journal of Macroeconomics 7(1). Perotti, R. (1999). Fiscal Policy in Good Times and Bad. The Quarterly Journal of Economics 114(4), 1399-1436.

Pesaran, M. H. and R. Smith (1995). Estimating Long-Run Relationships From Dynamic Heterogeneous Panels. Journal of econometrics 68(1), 79-113.

Primiceri, G. E. (2005). Time Varying Structural Vector Autoregressions and Monetary Policy. Review of Economic Studies 72(252), 821-852. 
Ramey, V. A. and S. Zubairy (2018). Government Spending Multipliers in Good Times and in Bad: Evidence from US Historical Data. Journal of Political Economy 126(2), 850-901. Rubio-Ramírez, J. F., D. F. Waggoner, and T. Zha (2010). Structural Vector Autoregressions: Theory of Identification and Algorithms for Inference. Review of Economic Studies 77(2), 665-696.

Sá, F., P. Towbin, and T. Wieladek (2014, apr). Capital Inflows, Financial Structure and Housing Booms. Journal of the European Economic Association 12(2), 522-546.

Stock, J. H. and M. W. Watson (2005). Implications of Dynamic Factor Models for VAR Analysis. NBER Working Papers 11467.

Sutherland, A. (1997). Fiscal crises and aggregate demand: can high public debt reverse the effects of fiscal policy? Journal of Public Economics 65(2), 147 - 162.

Towbin, P. and S. Weber (2013). Limits of Floating Exchange Rates; the Role of Foreign Currency Debt and Import Structure. Journal of Development Economics 101(C), 179194.

Woodford, M. (2011). Simple Analytics of the Government Expenditure Multiplier. American Economic Review 3(1), 1-35.

Wu, J. C. and F. D. Xia (2016). Measuring the Macroeconomic Impact of Monetary Policy at the Zero Lower Bound. Journal of Money, Credit and Banking 48(2-3), 253-291.

Wu, J. C. and F. D. Xia (2017). Time-Varying Lower Bound of Interest Rates in Europe. Chicago Booth Research Paper No. 17-06. 


\section{Appendix}

\section{A Data}

\section{A.1 Endogenous Variables}

Our variables of interest are gross domestic product, net taxes and government spending. As standard in the literature we construct net taxes as the sum of government receipts of direct and indirect taxes minus transfers to businesses and individuals. The government spending series is constructed as the sum of government gross fixed capital formation and government consumption. All the variables are downloaded from the Eurostat database available on the Thomson Reuters Datastream Economics database and are transformed in real terms using the implicit GDP price deflator. Then they are normalized by diving by real potential GDP.

\section{A.2 Exogenous Variables}

We use as exogenous variables the forecast of the annualized growth rate of total government expenditure over GDP produced by the Economist Intelligence Unit. In particular, we create a series where in each quarter we compute the average forecast for the current year over the past 12 months. Our interaction term is the European Central Bank's shadow rate developed by $\mathrm{Wu}$ and Xia (2017). The other exogenous variables are the U.S. output gap, and the U.S. inflation downloaded from the Federal Reserve Bank of St. Louis database, and the U.S. Shadow Rate developed by Wu and Xia (2016).

\section{A.3 Informational Dataset}

The informational dataset we used to extract common factors is composed by 250 series downloaded from the Eurostat database available on the Thomson Reuters Datastream Economics database. Specifically we downloaded the following variables for each country considered:

- National Account: Domestic Demand; Export of Goods and Services; Imports of Goods and Services; Gross Capital Formation; Final Consumption Expenditure of Households.

- Government Statistics: Government Consolidated Gross Debt: Central Govt.

- Output and income: Industrial Production Index: Manufacturing; Industrial Production Index: Mig-Intermediate Goods; Nominal Unit Labor Cost based on persons; 
Production - Total Industry Excl. Construction; Production of Total Construction; Wages and Salaries; Change in Inventories.

- Employment and hours: Early Estimates of Labor Productivity - Total Economy; Employees Domestic Concept; Unemployment: Total.

- Stock prices: S\&P BMI - Price Index.

- Exchange rates: NEER: 28 Trading Partners; NEER: 37 Trading Partners.

- Money and credit quantity aggregates: Money Supply: M1 - Contribution to Euro M1; Money Supply: M2 - Contribution to Euro M2; Money Supply: M3 - Contribution to Euro M3; Official Reserve Assets.

- Interest Rate: Harmonized Government 10-Year Bond Yield.

The following series are converted from monthly to quarterly frequency: Harmonized Government 10-Year Bond Yield; Industrial Production Index: Manufacturing; Industrial Production Index: Mid-Intermediate Goods; Money Supply: M1 - Contribution to Euro M1; Money Supply: M2 - Contribution to Euro M2; Money Supply: M3 - Contribution to Euro M3; Official Reserve Assets. Moreover, the S\&P BMI - Price Index series is converted from daily to quarterly frequency. Where appropriate we transform variables to guarantee stationarity tested by the Dickey and Fuller (1979) and Kwiatkowski et al. (1992) tests.

\section{A.4 Business Cycle Indicator}

Our aggregate indicator of business cycle is computed as $\sum_{i=1}^{10} \frac{G D P_{i}}{G D P_{i}^{\text {trend }}}$, where $i$ are the countries considered in our sample, and $G D P_{i}, G D P_{i}^{\text {trend }}$ are the real GDP and the real potential GDP of each country, respectively. In general, if our aggregate indicator is large and positive (large and negative), it means that most countries are in expansion (recession). 


\section{B Additional Robustness Checks}

Table B.1: Conditional Correlations of Cumulated Multipliers with the Contemporaneous Shadow Rate and the Contemporaneous Business Cycle.

\begin{tabular}{|c|c|c|c|}
\hline Horizon & $H$ & $\operatorname{corr}\left(\hat{\varepsilon}_{t}^{\mathcal{M}_{H} \mid b c}, s r_{t}\right)$ & $\operatorname{corr}\left(\hat{\varepsilon}_{t}^{\mathcal{M}_{H} \mid s r}, b c_{t}\right)$ \\
\hline 1 year & 4 & $\begin{array}{c}0,2264 \\
(0,0998)\end{array}$ & $\begin{array}{l}-0,1329 \\
(0,3381)\end{array}$ \\
\hline 2 years & 8 & $\begin{array}{l}-0,6732 \\
(0,0000)\end{array}$ & $\begin{array}{l}-0,2688 \\
(0,0494)\end{array}$ \\
\hline 3 years & 12 & $\begin{array}{l}-0,7893 \\
(0,0000)\end{array}$ & $\begin{array}{l}-0,3265 \\
(0,0160)\end{array}$ \\
\hline 4 years & 16 & $\begin{array}{l}-0,8050 \\
(0,0000)\end{array}$ & $\begin{array}{l}-0,2697 \\
(0,0486)\end{array}$ \\
\hline 5 years & 20 & $\begin{array}{l}-0,7953 \\
(0,0000)\end{array}$ & $\begin{array}{l}-0,2327 \\
(0,0904)\end{array}$ \\
\hline
\end{tabular}

Notes: Conditional correlations are obtained running two auxiliary regressions and computing the correlation coefficients between the residuals of these regressions and the variables of interest. The first regresses the cumulated multiplier on a constant and the contemporaneous business cycle indicator. The correlation is computed between the residuals of this regression and the contemporaneous shadow rate. The second regresses the cumulated multiplier on a constant and the contemporaneous shadow rate. The correlation is computed between the residuals of this regression and the contemporaneous business cycle indicator. These computations are replicated at different horizons $H$ for the cumulated multipliers. P-values are in parentheses.

Table B.2: Robustness Checks on Conditional Correlations of Cumulated Multipliers with the Contemporaneous Shadow Rate and the Contemporaneous Business Cycle.

\begin{tabular}{|c|c|c|c|c|c|c|c|}
\hline & & \multicolumn{2}{|c|}{$\begin{array}{c}\text { Sign restrictions } \\
\text { imposed for } 2 \text { quarters }\end{array}$} & \multicolumn{2}{|c|}{$\begin{array}{l}\text { Lag structure of } \\
2 \text { quarters }\end{array}$} & \multicolumn{2}{|c|}{$\begin{array}{l}\text { Including 10-year } \\
\text { gov. bond yields }\end{array}$} \\
\hline Horizon & $H$ & $\hat{\varepsilon}_{t}^{\mathcal{M}_{H} \mid b c}, s r_{t}$ & $\hat{\varepsilon}_{t}^{\mathcal{M}_{H} \mid s r}, b c_{t}$ & $\hat{\varepsilon}_{t}^{\mathcal{M}_{H} \mid b c}, s r_{t}$ & $\hat{\varepsilon}_{t}^{\mathcal{M}_{H} \mid s r}, b c_{t}$ & $\hat{\varepsilon}_{t}^{\mathcal{M}_{H} \mid b c}, s r_{t}$ & $\hat{\varepsilon}_{t}^{\mathcal{M}_{H} \mid s r}, b c_{t}$ \\
\hline 1 year & 4 & $\begin{array}{c}0,1730 \\
(0,2110)\end{array}$ & $\begin{array}{l}-0,3690 \\
(0,0060)\end{array}$ & $\begin{array}{l}-0,4435 \\
(0,0008)\end{array}$ & $\begin{array}{l}-0,3391 \\
(0,0121)\end{array}$ & $\begin{array}{c}0,5022 \\
(0,0001)\end{array}$ & $\begin{array}{l}-0,4617 \\
(0,0004)\end{array}$ \\
\hline 2 years & 8 & $\begin{array}{l}-0,5519 \\
(0,0000)\end{array}$ & $\begin{array}{l}-0,5035 \\
(0,0001)\end{array}$ & $\begin{array}{l}-0,7689 \\
(0,0000)\end{array}$ & $\begin{array}{l}-0,1933 \\
(0,1614)\end{array}$ & $\begin{array}{c}0,1709 \\
(0,2167)\end{array}$ & $\begin{array}{l}-0,5185 \\
(0,0001)\end{array}$ \\
\hline 3 years & 12 & $\begin{array}{l}-0,7774 \\
(0,0000)\end{array}$ & $\begin{array}{l}-0,5346 \\
(0,0000)\end{array}$ & $\begin{array}{l}-0,7646 \\
(0,0000)\end{array}$ & $\begin{array}{l}-0,2190 \\
(0,1116)\end{array}$ & $\begin{array}{l}-0,1495 \\
(0,2807)\end{array}$ & $\begin{array}{l}-0,5249 \\
(0,0000)\end{array}$ \\
\hline 4 years & 16 & $\begin{array}{l}-0,7785 \\
(0,0000)\end{array}$ & $\begin{array}{l}-0,5049 \\
(0,0001)\end{array}$ & $\begin{array}{l}-0,7235 \\
(0,0000)\end{array}$ & $\begin{array}{l}-0,1320 \\
(0,3412)\end{array}$ & $\begin{array}{l}-0,3283 \\
(0,0154)\end{array}$ & $\begin{array}{l}-0,5077 \\
(0,0001)\end{array}$ \\
\hline 5 years & 20 & $\begin{array}{l}-0,7675 \\
(0,0000)\end{array}$ & $\begin{array}{l}-0,4655 \\
(0,0004)\end{array}$ & $\begin{array}{l}-0,6706 \\
(0,0000)\end{array}$ & $\begin{array}{l}-0,1224 \\
(0,3778)\end{array}$ & $\begin{array}{l}-0,3970 \\
(0,0030)\end{array}$ & $\begin{array}{l}-0,4837 \\
(0,0002)\end{array}$ \\
\hline
\end{tabular}

Notes: Conditional correlations are obtained running two auxiliary regressions and computing the correlation coefficients between the residuals of these regressions and the variables of interest. The first regresses the cumulated multiplier on a constant and the contemporaneous business cycle indicator. The correlation is computed between the residuals of this regression and the contemporaneous shadow rate. The second regresses the cumulated multiplier on a constant and the contemporaneous shadow rate. The correlation is computed between the residuals of this regression and the contemporaneous business cycle indicator. These computations are replicated at different horizons $H$ for the cumulated multipliers. P-values are in parentheses. 